\title{
Consulta de enfermagem, prescrição de medicamentos e solicitação de exames por enfermeiros na atenção básica à saúde
}

Ivo Aguiar Lopes Borges ${ }^{1}$

Reflexão teórica sobre consulta de enfermagem, prescrição de medicamentos e solicitação de exames por enfermeiros, fundamentada nos marcos legais da política nacional de atenção básica à saúde no âmbito da Estratégia Saúde da Família. Aborda os marcos legais da Política Nacional de Atenção Básica, os aspectos legais das atribuições dos enfermeiros na estratégia saúde da família, a consulta e processo de enfermagem como modelo holístico a serviço da saúde, os requisitos para a prática de enfermagem na atenção básica à saúde e a reação de profissionais de saúde ao novo paradigma proposto.

Descritores: Enfermagem; Legislação e jurisprudência; Recursos humanos.

\begin{abstract}
Consultation of nursing, lapsing of medicines and request of examinations for nurses in the basic attention to the health Theoretical reflection on nursing consultation, medicine lapsing and request of examinations for nurses, based on legal landmarks of the national politics of basic attention to the health in the scope of the Strategy Health of the Family. It approaches landmarks of the National Politics of Basic Attention, the legal aspects of the attributions of the nurses in the strategy health of the family, the consultation and process of nursing legal as holistic model the service of the health, the requirements for practical of nursing in the basic attention to the health and the reaction of professionals of health to the new considered paradigm.
\end{abstract}

Descriptors: Nursing; Legislation and jurisprudence; Manpower.

\begin{abstract}
Consulta del oficio de enfermera, del paso de medicinas y de la petición de las examinaciones para las enfermeras en la atención básica a la salud Reflexión teórica en la consulta del oficio de enfermera, el paso de la medicina y la petición de las examinaciones para las enfermeras, basadas en las señales legales de la política nacional de la atención básica a la salud en el alcance de la salud de la estrategia de la familia. Se acerca a las señales de la política nacional de la atención básica, los aspectos legales de las atribuciones de las enfermeras en la salud de la estrategia de la familia, la consulta y el proceso de cuidar legales como modelo holístico el servicio de la salud, los requisitos para práctico del cuidado en la atención básica a la salud y la reacción de profesionales de la salud al nuevo paradigma considerado.
\end{abstract}

Descriptores: Enfermería; Legislación y jurisprudência; Recursos humanos.

\section{INTRODUÇÃO}

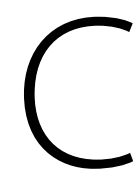

onsulta de enfermagem, prescrição de medicamentos e solicitação de exames por enfermeiros no âmbito da Estratégia Saúde da Família (ESF) são procedimentos que se inserem num modelo inovador de atenção à saúde, que representa verdadeira mutação do conceito de atenção à saúde vigente há centenas de anos.

Tal paradigma, adotado no seio da Política Nacional de Atenção Básica $(\mathrm{PNAB})^{(1)}$ possui profundas raízes nos modernos postulados da ciência pós-moderna, representada fundamentalmente pelo deslocamento da abordagem biologicista- mecanicista para a abordagem holística de compreensão do homem como um ser indivisível(2), configurando-se como um processo de ruptura epistemológica.

Romper com o velho para implantar o novo pode causar resistência e atemorizar pessoas que por ideologias próprias mantêm firmes posicionamentos, sobretudo para a preservação de interesses pessoais e corporativos. Corolário de tal situação são as inúmeras ações judiciais contra práticas inovadoras no âmbito da saúde.
Por este prisma de reflexão, ainda que consagradas em Lei, a consulta de enfermagem, a prescrição de medicamentos e solicitação de exames por enfermeiros no âmbito da ESF tem sido alvo de severas críticas, sobretudo da categoria médica que, a despeito da legislação pertinente à matéria, desfere pesadas $\mathrm{e}$ infundadas críticas contra o novo paradigma em saúde pública.

A despeito do reacionarismo, tal procedimento, de competência dos enfermeiros possui amplo amparo na legislação brasileira constituindo, inclusive, prerrogativa dos profissionais da enfermagem. Prerrogativa tal que seu desrespeito condiciona os ofensores às severas penas, também previstas em Lei.

\section{Marcos legais da Política Nacional de Atenção Básica}

A PNAB expressa a reconstrução da Atenção Básica à Saúde como uma proposta do governo federal aos municípios para implementar estratégias de reorganização dos serviços e de reorientação das práticas profissionais neste nível de assistência.

Todos os postulados desta política se encontram em

1 Advogado. Assessor Legislativo do Conselho Federal de Enfermagem. Pós-Graduado em Direito Tributário pelo Instituto Brasileiro de Estudos Tributários - IBET. Membro da Comissão de Estudos Tributários e de Defesa do Contribuinte da OAB Seccional, MT. 
consonância com o processo de mudança do modelo assistencial que orienta o sistema de saúde vigente e que vem sendo discutido amplamente desde a década de 1980, pelo conjunto de atores e sujeitos sociais comprometidos com um novo modelo que valorize as ações de promoção e proteção da saúde, prevenção das doenças e atenção integral às pessoas. O marco histórico da ruptura com o modelo hegemônico de saúde data

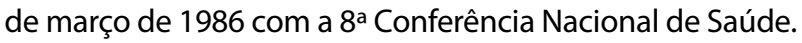

Estes pressupostos, tidos como capazes de produzir um impacto positivo na orientação do novo modelo e na superação do anterior, calcado na supervalorização das práticas da assistência curativa, especializada e hospitalar, e que induz ao excesso de procedimentos tecnológicos e medicamentosos e, sobretudo, na fragmentação do cuidado, encontra, em relação aos recursos humanos para o Sistema Único de Saúde (SUS), outro desafio, qual seja, a sua consolidação.

Legalmente, a PNAB encontra lastro na Portaria GM/MS no 648 de 28 de março de 2006. Em seu Capítulo I, Item 1 - dos princípios gerais, a Portaria evidencia os pressupostos deste novo paradigma proposto para o cuidado em saúde, que se orienta pelas diretrizes do SUS:

"A Atenção Básica caracteriza-se por um conjunto de ações de saúde, no âmbito individual e coletivo, que abrangem a promoção e a proteção da saúde, a prevenção de agravos, o diagnóstico, o tratamento, a reabilitação e a manutenção da saúde. É desenvolvida por meio do exercício de práticas gerenciais e sanitárias democráticas e participativas [...] Utiliza tecnologias de elevada complexidade e baixa densidade, que devem resolver os problemas de saúde de maior frequência e relevância em seu território. É o contato preferencial dos usuários com os sistemas de saúde".

A Portaria esclarece que a Atenção Básica tem a Saúde da Família como estratégia prioritária para sua organização de acordo com os preceitos do Sistema Único de Saúde. Todo o Capítulo II da Portaria é reservado à Estratégia de Saúde da família, asseverando que a ESF visa reorganizar a Atenção Básica no país.

Nos aspectos legais das atribuições dos enfermeiros na ESF, justamente no âmbito da ESF, o papel primordial dos profissionais da enfermagem é destacado, notadamente por meio da Portaria GM/MS no 1.625 que alterou a Portaria GM/MS no 648 que, em seu art. $1^{\circ}$, alterando o texto da Portaria GM/MS no 648, define as atribuições do enfermeiro:

"Art. 1 Alterar o Anexo I da Política Nacional de Atenção Básica (...) que passa a vigorar com a seguinte redação:

Do enfermeiro:

I - realizar assistência integral às pessoas e famílias na USF e, quando indicado ou necessário, no domicílio e/ou nos demais espaços comunitários.

II - realizar consultas de enfermagem, solicitar exames complementares e prescrever medicações, observadas as disposições legais da profissão e conforme os protocolos ou outras normativas técnicas estabelecidas pelo Ministério da Saúde, os gestores estaduais, os municipais ou os do Distrito Federal".

Em consonância com um novo paradigma de atenção em saúde, a Portaria define expressamente atribuições de destaque aos enfermeiros no âmbito da ESF, em coro com Capra ${ }^{(3)}$, de que um número crescente de enfermeiras está decidindo tornarse terapeutas independentes, procurando se orientar em sua prática por uma abordagem holística.

Estas atribuições, porém, não exsurgem tão somente da Portaria do Ministério da Saúde, diploma normativo secundário, de estatura inferior à lei e que não pode inovar no ordenamento jurídico. Tais disposições encontram-se igualmente contidas no art. 11, incisos I alínea " $\mathrm{i}$ " e inciso II, alínea " $\mathrm{c}$ ", verbis: Art. 11 - O Enfermeiro exerce todas as atividades de enfermagem cabendo- Ihe: I - privativamente: ... omissis ... consulta de enfermagem; II - como integrante da equipe de saúde: c) prescrição de medicamentos estabelecidos em programas de saúde pública e em rotina aprovada pela instituição de saúde.

Ainda que se questione o teor da norma contida na Portaria GM/MS no 648/2006 em razão da impossibilidade de inovação jurídica veiculada por instrumento normativo secundário, certo é que tais disposições decorrem da Lei, veículo considerado como norma primária, capaz de inovar no mundo jurídico.

\section{Consulta e processo de enfermagem: o modelo holístico a serviço da saúde}

Depreende-se da Portaria GM/MS $n^{\circ}$ 648/2006 algumas das práticas e características da ESF, a saber: manter atualizado o cadastramento das famílias e dos indivíduos e utilizar, de forma sistemática, os dados para a análise da situação de saúde considerando as características sociais, econômicas, culturais, demográficas e epidemiológicas do território; prática do cuidado familiar ampliado, efetivada por meio do conhecimento da estrutura e da funcionalidade das famílias às quais se visa propor intervenções que influenciem os processos de saúde doença dos indivíduos, das famílias e da própria comunidade; promoção e estímulo à participação da comunidade no controle social, no planejamento, na execução e na avaliação das ações; trabalho interdisciplinar e em equipe, integrando áreas técnicas e profissionais de diferentes formações; valorização dos diversos saberes e práticas na perspectiva de uma abordagem integral e resolutiva, possibilitando a criação de vínculos de confiança com ética, compromisso e respeito; promoção e estímulo à participação da comunidade no controle social, no planejamento, na execução e na avaliação das ações; e acompanhamento e avaliação sistemática das ações implementadas, visando à readequação do processo de trabalho.

Para a consecução destes objetivos é incontestável que o instrumento adequado é o processo de enfermagem. Segundo Nóbrega, Processo de enfermagem ${ }^{(4)}$ :

“[...] é o instrumento profissional que guia a prática de 
enfermagem e pode fornecer autonomia profissional e concretizar a proposta de promover, manter ou restaurar o nível de saúde do paciente, como também documentar a prática profissional, visando à avaliação da qualidade da assistência prestada.

[...] possui um enfoque holístico; ajuda a assegurar que as intervenções sejam elaboradas para o indivíduo e não apenas para a doença; apressa os diagnósticos e o tratamento dos problemas de saúde potenciais e vigentes, reduzindo a incidência e a duração da hospitalização; promove a flexibilidade do pensamento independente; melhora a comunicação e previne erros, omissões e repetições desnecessárias".

Sobre a matéria, a Resolução COFEN n 358/09 positivou o método cientííco da enfermagem estabelecendo, em seu art. $1^{\circ}$ que "o Processo de Enfermagem deve ser realizado de modo deliberado e sistemático, em todos os ambientes, públicos ou privados, em que ocorre o cuidado profissional de Enfermagem". Enquanto método da Ciência da Enfermagem, o Processo de Enfermagem organiza-se em cinco etapas inter-relacionadas, interdependentes e recorrentes: a coleta de dados de enfermagem (ou histórico de enfermagem); o diagnóstico de enfermagem; planejamento de enfermagem; implementação e avaliação da enfermagem.

Tais etapas são consentâneas com as práticas da ESF de organizar dados relativos à saúde (coleta de dados), prática do cuidado familiar ampliado, efetivada por meio do conhecimento da estrutura e da funcionalidade das famílias às quais visa propor intervenções que influenciem os processos de saúde doença dos indivíduos (diagnóstico e implementação), promoção e estímulo à participação da comunidade no controle social, no planejamento, na execução e na avaliação das ações (planejamento) e, e acompanhamento e avaliação sistemática das ações implementadas, visando à readequação do processo de trabalho (avaliação).

Assim, antes de constituir um privilégio, a atuação dos enfermeiros no ESF e a outorga de competência para que realizem consultas, prescrição de medicamentos e solicitação de exames é, o pressuposto para a implementação de um novo modelo em saúde voltada para o indivíduo e família, e não para a doença.

Como requisitos para a prática de Enfermagem na Atenção Básica à Saúde como consoante demonstrado, os enfermeiros possuem, nos termos da Portaria GM/MS no 1.625 , competências para realizar consultas de enfermagem, solicitar exames complementares e prescrever medicações, observadas as disposições legais da profissão e conforme os protocolos ou outras normativas técnicas estabelecidas pelo Ministério da Saúde, os gestores estaduais, os municipais ou os do Distrito Federal.

Tais protocolos e/ou normativas técnicas, nos termos da própria Portaria 648/2006 são de responsabilidade do gestor de saúde e, em âmbito nacional, espraiam-se nos Cadernos de Atenção Básica do Ministério da Saúde. Dentre tais, citamos apenas dois, dos inúmeros existentes:

a) Cadernos atenção básica, do cuidado integral ao paciente com diabetes e sua família, no 16, ano 2006 que à página 47 define as atribuições do enfermeiro, dentre tais, realizar consulta de enfermagem com pessoas com maior risco para diabetes tipo 2 identificadas pelos agentes; realizar consulta de enfermagem, abordando fatores de risco; solicitar, durante a consulta de enfermagem, os exames de rotina, repetir a medicação de indivíduos controlados e sem intercorrências;

b) Manual técnico para controle da tuberculose, cadernos de atenção básica $n^{\circ} 6$, $6^{\text {a }}$ edição, 2002, que em seu item 10 define como atribuições do enfermeiro solicitar baciloscopia dos sintomáticos respiratórios para diagnóstico, realizar consulta de enfermagem mensal, dispensar os medicamentos para o doente e solicitar o exame de escarro mensal.

Assim sendo, o enfermeiro possui papel preponderante na universalização do acesso à saúde na medida em que, munido do processo de enfermagem, pode praticar atos objetivando a democratização do acesso aos meios promotores da saúde. Logo, as competências reservadas à enfermagem, portanto, são condições essenciais à universalização do acesso à saúde. Advogar o contrário é circunscrever o cuidado em saúde à uma pequena parcela da população brasileira.

\section{A reação ao novo paradigma proposto}

A atuação do enfermeiro na Atenção Básica representa uma mudança no paradigma da atenção e cuidado em saúde e isto the confere um papel de destaque nas equipes multidisciplinares propostas pelo Ministério da Saúde. Este fato, porém, provoca reação em uma ínfima parcela de profissionais de saúde. Sem a correta compreensão das mudanças que experimentamos, questionam, inclusive judicialmente, as competências atribuídas aos enfermeiros. A exemplo, temos o Mandado de Segurança de $n^{\circ}$ 2006.34.00.034729-1 em que o Conselho Federal de Medicina questionou a legalidade da Resolução COFEN no 271/02. Em tal ação, o CFM obteve liminar para suspender a Resolução COFEN no 271/02. Ocorre que, inobstante referida suspensão, a outorga de competência para a prática da consulta, prescrição de medicamentos e solicitação de exames decorre da Lei, conforme demonstrado, e da Portaria MS no 1.625/07. O comando judicial que suspendeu a Resolução não espraiou seus efeitos sobre a vigência da Lei. Em razão da situação, o Cofen adotou a providência, inócua para as prerrogativas dos enfermeiros, de, através da Resolução Cofen no 317/07, revogar a Resolução COFEN no 271/02. Inócua, pois, subsistiu a Lei do exercício profissional garantindo as prerrogativas dos enfermeiros.

Inúmeras outras ações judiciais contra a Resolução COFEN e até Portarias Estaduais e Municipais foram intentadas pelos órgãos de representação da medicina. Emblemática, para o caso, porém, foi a atitude adotada pelo Sindicato dos Médicos de Vila Velha, Espírito Santo, contra uma enfermeira que tão somente atuou no exercício regular de seu direito. $\mathrm{Na}$ ocasião, o referido sindicato apresentou denúncia-crime contra a enfermeira alegando exercício 
ilegal da medicina diante do fato de que a profissional prescrevera medicamento no âmbito do ESF. A denúncia, após esclarecimentos ao Ministério Público, foi arquivada e a enfermeira buscou a prestação da tutela jurisdicional para responsabilizar o Sindicato dos Médicos em razão do vilipêndio às suas prerrogativas profissionais propondo ação de indenização por danos morais e materiais que, instância recursal, julgada da seguinte forma:

EMENTA

DANO MORAL. DANO MATERIAL. ENFERMEIRA LIGADA AO PSF. NOTITIA CRIMINIS. EXERCÍCIO ILEGAL DA MEDICINA. LICITUDE DA CONDUTA ILEGITIMIDADE PASSIVA DO PRESIDENTE DO CRM/ES.

(...) - O dever de indenizar, no caso, deve ser creditado à entidade, CRM/ES, que, por meio de seu Presidente, em exercício à época dos fatos, apresentou notitia criminis, acusando a autora, enfermeira inscrita no Conselho Regional de Enfermagem do Espírito Santo, de exercício ilegal da medicina, por estar realizando consultas, diagnosticando, prescrevendo medicamentos e solicitando exames clínicos.

(...) - Ausentes, no caso, elementos que comprovem a prática ilegal da medicina e de crime contra a saúde pública. O Réu não atentou para a legislação que rege a matéria concernente às atribuições da atividade de enfermeira ligada ao Programa de Saúde da Família.

(...) - Até mesmo o Ministério Público, defensor máximo dos interesses da sociedade, não identificou qualquer conduta ilícita por parte da autora, razão por que pediu o arquivamento dos autos, conforme se insere da cópia do inquérito policial no 1002739/02, juntado aos autos.

(...) - Ainda que o réu tenha agido dentro de suas atribuições legais, ao intentar ação fiscalizadora e oferecer notitia criminis com o fito de apurar eventual responsabilidade da autora no exercício de suas atividades profissionais, entendo, que, na espécie, há a demonstração cabal de que a instauração do procedimento se deu de forma injusta, despropositada e quiçá leviana, por estar a autora amparada em leis federais e portarias do Ministério da Saúde. A autoridade do CRM/ES não se deu ao trabalho de apurar se a autora estaria amparada por alguma legislação para praticar os atos reputados de ilegais. Ao contrário, imputou-lhe, errada e negligentemente, a prática de exercício ilegal da medicina, submetendo a autora, tida como excelente profissional, segundo depoimentos colhidos de testemunhas intimadas no Inquérito Policial, desnecessariamente, a todos os constrangimentos que tal procedimento inegavelmente traz para o indivíduo, motivo por que o Réu deve responder pelo dano causado, impondose a indenização por danos morais, além daquela por danos materiais já reconhecida pelo Juízo a quo, referente aos gastos com advogado, conforme recibo de pagamento juntado aos autos, no valor de $\mathrm{R} \$ 6.000,00$ (seis mil reais).

(...) - Na espécie, considero que a indenização a título de dano moral, que fixo em $\mathrm{R} \$ 10.000,00$ (dez mil reais), guarda proporcionalidade e razoabilidade com os fatos.

- Nega-se provimento ao recurso do CRM/ES e dá-se parcial provimento ao recurso da autora.

ACÓRDÃO

Vistos e relatados estes autos, em que são partes as acima indicadas; Decide a Quinta Turma Especializada do Tribunal
Regional Federal da $2^{\mathrm{a}}$ Região, por unanimidade, negar provimento ao recurso do CRM/ES e à remessa necessária e dar parcial provimento ao recurso da autora, nos termos do Voto do Relator.

(TRF2: AC 2002.50.01.009930-3; Rel. Des.: FERNANDO MARQUES)

O julgamento em questão é emblemático a Enfermagem, demonstrando cabalmente a competência dos enfermeiros para a prática da consulta da enfermagem, prescrição de medicamentos e solicitação de exames no âmbito da ESF. Competência esta outorgada pela Lei.

De acordo com os fatos, observa-se que qualquer ato atentatório às prerrogativas da enfermagem, caso praticado por agente público ou privado, possa caracterizar os crimes de abuso de autoridade ou constrangimento ilegal, assim como assédio moral.

\section{Conclusão}

Advoga-se hodiernamente, por todo um conjunto de profissionais esclarecidos, a necessidade de adoção de um novo modelo de atenção e cuidado à saúde. Este modelo tem na abordagem holística sua pilastra central. Como resultado, a política brasileira para a saúde pública adotou a visão sistêmica, positivando tal paradigma na Política Nacional de Atenção Básica, que tem na ESF sua estratégia prioritária.

Como tal, a multidisciplinaridade assume papel central, atribuindo aos enfermeiros posição de destaque nas ações preventivas de saúde. Isto porque, característica do saber da enfermagem, notadamente em razão de seu método centrado no Processo de Enfermagem, o enfermeiro é o profissional mais capacitado para dar as respostas que a abordagem de promoção da saúde e preventiva reclama.

E é por tal razão, e não pela manutenção pura e simples de um privilégio de categorias profissionais, que os enfermeiros tiveram sua atuação ampliada no sistema de saúde, cabendo-lhe realizar consulta de enfermagem, prescrição de medicamentos e solicitação de exames no âmbito da ESF. Tal medida se destina, portanto, ao interesse público da promoção da saúde da população. A defesa de tais prerrogativas, assim, é a defesa da saúde de milhões de brasileiros, cabendo a todas as entidades representativas da enfermagem a adoção de uma postura firme e intransigente nesta defesa, notadamente, nos Conselhos Regionais de Enfermagem.

\section{Referências}

1. Brasil. Ministério da Saúde. Portaria GM/MS n 648 de 28 de março de 2006.

2. Lopes Neto D, Pagliuca LMF. Abordagem holística do termo pessoa em

um estudo empirico: uma análise crítica. Rev Latinoam Enfermagem 2002

novembro-dezembro; 10(6):825-30.

3. Capra F. O ponto de mutação: a ciência, a sociedade e a cultura emergente. São Paulo: Cultrix, 1997.

4. Nóbrega MML, Silva KL (Org). Fundamentos do cuidar em enfermagem.

Belo Horizonte: ABEn; 2008/2009. 